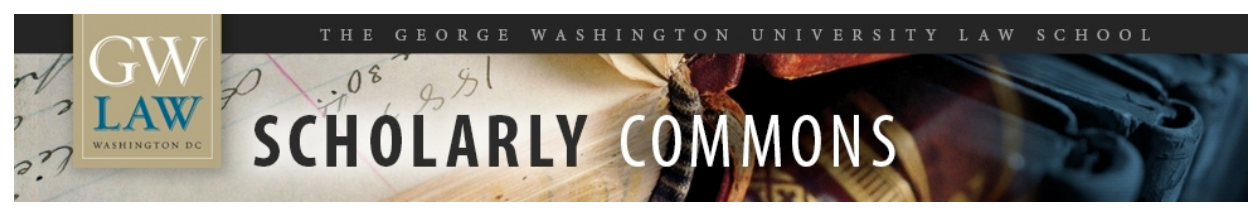

\title{
Caught in the Crossfire: A Defense of the Cultural Theory of Gun- Risk Perceptions
}

Donald Braman

George Washington University Law School, dbraman@law.gwu.edu

Dan M. Kahan

Yale Law School

Follow this and additional works at: https://scholarship.law.gwu.edu/faculty_publications

Part of the Law Commons

\section{Recommended Citation}

151 U. Pa. L. Rev. 1395-1417 (2003)

This Article is brought to you for free and open access by the Faculty Scholarship at Scholarly Commons. It has been accepted for inclusion in GW Law Faculty Publications \& Other Works by an authorized administrator of Scholarly Commons. For more information, please contact spagel@law.gwu.edu. 


\section{RESPONSE}

\section{CAUGHT IN THE CROSSFIRE: A DEFENSE OF THE CULTURAL THEORY OF GUN-RISK PERCEPTIONS}

\section{DAN M. KAHAN \& DONALD BRAMAN}

Anyone who despairs of the prospect for consensus in the American gun debate should be heartened by the commentaries on our article. ${ }^{1}$ Cook and Ludwig finally see eye-to-eye with Lott and Mustard.

Of course, the consensus among the commentators that we must be wrong about something doesn't hearten us. We are truly gratified by their thoughtful commentaries, though, and we will now try to return the favor-by returning fire.

\section{A Cultural Theory of SMOKInG- ANd UnSAFe-SeX-Risk PERCEPTIONS}

Cook and Ludwig think we are too quick to dismiss the power of empirical information to influence individuals' positions on gun control. "[W]e know," they write, "that people's attitudes and behaviors about smoking and unprotected sex have changed dramatically over time" as a result of "epidemiological research about the health risks associated with each of these activities." If "statistical evidence can affect people's attitudes and behaviors even in areas where cultural attitudes run deep,"” why assume that some future expert consensus on the consequences of gun control can't do the same?

It turns out, though, that we don't know that changes in smoking and sexual practices reflect the dissemination of information on health risks. On the contrary, public health professionals have concluded that managing the social meanings that individuals attach to smoking and unsafe sex is the only effective means of reducing such behavior, and that risk information abstracted from such cultural

${ }^{1}$ Dan M. Kahan \& Donald Braman, More Statistics, Less Persuasion: A Cultural Theory of Gun-Risk Perceptions, 151 U. PA. L. REV. 1291 (2003). (2003).

Philip J. Cook \& Jens Ludwig, Fact-Free Gun Policy?, 151 U. PA. L. REV. 1329, 1333

$$
{ }^{3} \text { Id. }
$$


resonances is inert. We will summarize the evidence for these conclusions. But first we want to show how one reasonably could have predicted it on the basis of Cook and Ludwig's own remarkable finding that our cultural orientation scales explain a significant amount of the variance in smoking and condom use. At that point, we'll be in a good position to clarify why our data suggests that empirical evidence on the consequences of guns can't settle the gun debate.

How should we expect empirical data to influence individual perceptions about the risks of smoking and unsafe sex? Consider the answers suggested by three different models of risk-information processing. The rational-weigher model assumes that individuals will respond to empirical data in a manner that maximizes their welfare. Accordingly, as information accumulates that smoking, unsafe sex, or some other activity is in fact riskier than individuals had previously believed, we can expect them to reduce participation to the optimum level. ${ }^{4}$

The irrational-weigher model, in contrast, asserts that individuals are incapable of responding to risk information in a way that maximizes their well-being. Cognitive biases will cause them systematically to underestimate certain risks, while volitional defects will prevent them from conforming their behavior to their judgment of what is in their interests. Accordingly, we should expect individuals not to be nearly so responsive to information about the risks of smoking or other dangerous activities as they should be. ${ }^{5}$

Finally, the cultural-evaluator model holds that individuals' risk perceptions are constructed by their cultural worldviews. Culture supplies the meanings-of courage or irresponsibility; of self-reliance or self-centeredness; of trust in or indifference to others-that determine the benefit that individuals derive from any particular form of risky behavior. Equally important, cultural orientations affect individuals' perceptions of the cost of such behavior by inclining them either to invest credence in or to dismiss evidence of risk. Data purporting to show the risks of smoking, unsafe sex, and the like will thus

\footnotetext{
${ }^{4}$ See W. Kip Viscusi, SMOKIng: Making The Risky Decision 18 (1992) (explaining that the "rational smoker" model assumes an individual who makes decisions "consistent with the standard assumptions in an idealized economics textbook model of consistent consumer choice" and who is "fully informed and makes rational decisions based on this information").

${ }^{5}$ See Jon D. Hanson \& Douglas A. Kysar, The Joint Failure of Economic Theory and Legal Regulation, in SMOKING: Risk, PERCEPTION, \& POLICY 229, 231 (Paul Slovic ed., 2001) ("Unlike the ideal practitioner of the scientific method ... individuals are subject to a variety of cognitive influences that frequently render their conclusions untrustworthy.").
} 
influence behavior, on this account, only when that data is congenial to individuals' visions of a properly ordered society. ${ }^{6}$

These views generate not only different predictions about how individuals will respond to information about risk but also different strategies for how to manage risk taking. The right strategy under the rational-weigher model is simply to furnish individuals with accurate information about smoking or unsafe sex, at which point they will make their own best judgment about the costs and benefits of engaging in it. The irrational-weigher model, because it denies that individuals can accurately form and act on cost-benefit judgments, favors regulatory management of smoking, unsafe sex, or other forms of risk taking consistent with expert cost-benefit determinations. ${ }^{7}$ The cultural-evaluator view says that only information or policies that influence the meanings that individuals attach to particular types of risk taking can change their attitudes or behavior. ${ }^{8}$

One can imagine various ways to test the relative power of these three models. But one way is simply to measure, as Ludwig and Cook have done, the relationship between such risk taking and individuals' cultural orientations. For it turns out that the models generate competing hypotheses on what that relationship will be.

The rational- and irrational-weigher models both imply that there shouldn't be a significant correlation between cultural orientations and either smoking or unsafe sex. As Cook and Ludwig point out, evidence of the health risks of these activities is massive and widely available. ${ }^{9}$ Because there is no reason to doubt that individuals of all cultural orientations have been exposed to it, there is no reason to think that individuals of only certain orientations and not others would revise their welfare-maximizing strategies in the manner predicted by the rational-weigher model. Likewise, there is no reason to believe

${ }^{6}$ Cf. Mary Douglas \& Aaron Wildavsky, Risk AND Culture 10 (1982) (positing a cultural approach that "can integrate moral judgments about how to live with empirical judgments about what the world is like").

7 See generally Cass R. Sunstein, The Laws of Fear, 115 HARV. L. REV. 1119 (2002) (reviewing Paul Slovic, The Perception of Risk (2000)) (discussing the disparity between the risk perceptions of experts and the general public, and its implications for risk regulation).

${ }^{8}$ Cf. DOUGLAS \& WiLDAVSKY, supra note 6, at 80-81 ("Science and risk assessment cannot tell us what we need to know about threats of danger since they explicitly try to exclude moral ideas about the good life.... Instead of being distracted by dubious calculations, we should focus our analysis just there ....").

${ }^{9}$ See Cook \& Ludwig, supra note 2, at 1333 (discussing the availability of scientific information on smoking through reports of the Surgeon General, advertisements, and warning labels). 
that cognitive biases and volitional defects are spread out unevenly across individuals of diverse cultural orientations, and thus no reason under the irrational-weigher model to believe that individuals of one orientation or another will react differently to risk information.

There obviously is a reason under the cultural-evaluator model, however, to expect individuals of different cultural orientations to react differently to smoking- and unsafe-sex-risk data. Individuals whose orientations invest smoking and unsafe-sex with (relatively) positive social meanings will either derive more compensating gain from such activities or be less likely to credit the information about the risks associated with them than will individuals whose cultural orientations invest smoking and unsafe sex with relatively negative social meanings. Alone among the three theories, then, the cultural-evaluator model predicts a significant correlation between worldview and willingness to smoke or engage in unsafe sex..$^{10}$

Lo and behold, that is exactly what Cook and Ludwig find in their regression model. So, if that were the only evidence one had about what influences such behavior, one would already have reason to believe that health-risk information, by itself, can't be expected to reduce smoking or increase safe sex.

In fact, however, social scientists and public health professionals have compiled many additional sources of evidence that confirm this interpretation of the Cook-Ludwig data. For example, the most recent and authoritative national survey on smoking among youth flatly contradicts claims that "young people reduce their smoking because of their heavy exposure to warnings about cigarette risks." comprehensive meta-data study on the effectiveness of smokingcession messages echoes these findings, concluding that information about the short-term and long-term health effects of smoking is just "not effective" in shaping behavior. ${ }^{12}$ And studies of smoking reduc-

${ }^{10}$ For an elaboration and defense of this methodology, see Hank C. JenkinsSmith, Modeling Stigma: An Empirical Analysis of Nuclear Waste Images of Nevada, in RISK, Media, and Stigma: Understanding Public Challenges to Modern Science AND TEChNOLOGY 107, 109-11 (James Flynn et al. eds., 2001).

${ }^{11}$ See Daniel Romer \& Patrick Jamieson, Advertising, Smoker Imagery, and the Diffusion of Smoking Behavior, in SMOKING: RISK, PERCEPTION, \& POLICY, supra note 5, at 127, 155 (reporting the results of the Youth Perception of Tobacco Risk Survey and the Perception of Tobacco Risk Survey, Age 14-22, both conducted in 1999).

${ }^{12}$ See Lisa K. Goldman \& Stanton A. Glantz, Evaluation of Antismoking Advertising Campaigns, 279 JAMA 772, 774-75 (1998) (reviewing the results of 186 focus groups and finding that ads describing health effects were not effective, but that depictions of "industry manipulation" were). 
tion show that the campaigns containing scientific information-ones Cook and Ludwig would presumably want to emulate for guns-"are not particularly effective at preventing young people from smoking or motivating adults to stop." ${ }^{\text {"13 }}$

If individuals aren't responsive to information about the consequences of smoking on their health, what are they responsive to? The answer, it appears, are the social meanings that they attach to smoking, meanings that have more to do with conceptions of the moral qualities of tobacco companies and smoking than with knowledge about smoking's health effects. Some of the best known and most effective of these antismoking ads contain no information about smoking risks; instead they show tobacco officials testifying that smoking is not addictive and has no proven health consequences. ${ }^{14}$ The information conveyed in such messages is clearly not empirical data about the harm cigarettes do, but information about the moral status of big tobacco that effectively taints cigarettes and smoking by association.

Striking evidence on the relative efficacy of social meaning versus health-risk-oriented smoking campaigns comes from California, where the tobacco industry convinced the state to pull moralizing antiindustry ads and substitute traditional health-information ads. This shift in advertising strategy-from culture-based appeals to health-risk ones-created a natural experiment on the relative power of each to influence behavior. The result? Smoking reductions slowed and, eventually, smoking rates increased. ${ }^{15}$

The literature on smoking also highlights the distinction we make between the manner in which risks can be either cognitively or morally derivative of social norms. ${ }^{16}$ It turns out that people are not impervi-

${ }^{13}$ Edith D. Balbach \& Stanton A. Glantz, Tobacco Control Advocates Must Demand High-Quality Media Campaigns: The California Experience, 7 TOBACCO CONTROL 397, 401 (1998); see also Frank A. Sloan et al., Information, Addiction, and "Bad Choices": Lessons from a Century of Cigarettes, 77 ECON. LETTERS 147, 148 (2002) (finding that "information on the harmful effects of cigarettes appears to have been a less important influence on demand than is generally believed").

${ }^{14}$ For an example of such an advertisement, featuring tobacco industry executives presenting testimony before Congress, see Real Media file: A Couple More Good Years: Example (Cal. Dep't of Health Servs. n.d.), available at http://apps.nccd.cdc .gov/MCRC/viewImage.asp?ProgName=SearchV.asp\&BlobID=111\&MediumID=1. For news accounts of a CDC study documenting the success of an anti-tobacco-industry campaign in Florida, see Florida Anti-Tobacco Ads Cited in Teen Smoking Drop, RECORD (Bergen County, N.J.), Apr. 2, 1999, at A10; Patricia J. Mays, Anti-Smoking Drive Working, CDC Says, ChatTanooga Times, Apr. 2, 1999, at A2.

${ }^{15}$ Balbach \& Glantz, supra note 13, at 400 fig.3.

${ }^{16}$ Kahan \& Braman, supra note 1, at 1296. 
ous to health-risk information. People's perceptions of factual health risks are moderately related to their exposure to clear and consistent information (moderated, we think, by the cognitive filters that comport with our norm-pervaded moral evaluations). ${ }^{17}$ But to the distress of public health advocates everywhere, increased knowledge about smoking's effects is minimally related-if at all-to smoking behavior. ${ }^{18}$ That is, unless the information conveyed by antismoking campaigns lends a negative moral valence to smoking, researchers have found little or no effect on behavior. ${ }^{19}$

Those interested in increasing condom usage and other "safer sex" practices have come to similar realizations. Again, meanings matter more than consequences. ${ }^{20}$ From couples involved in long-term relationships, ${ }^{21}$ to women working in the sex industry, ${ }^{22}$ to junkies

${ }^{17} I d$. at $1314-16$.

${ }^{18}$ See E.J. Mundell, Early Antismoking Education May Be Ineffective, Action on Smoking Health (Sept. 22, 2000), at http://no-smoking.org/sept00/09-22-00-2.html (describing results of a study showing that even a "clear understanding of the dangers of smoking" doesn't stop youth from smoking). These findings are not limited to the United Sates or other Western nations. See, e.g., Fang-Hsin Lee \& Hsiu-Hung Wang, Effects of Health Education on Prevention of Smoking Among Eighth-Grade Students, 18 KAOHSIUNG J. MED. SCI. 295, 295 (2002) ("[W] hile health education could significantly enhance students' smoking knowledge, it did not significantly change the students' nonsmoking attitudes, decision-making capabilities, or intention not to smoke.").

${ }^{19}$ Supra notes $14-15$ and accompanying text.

${ }^{20}$ Indeed many researchers find that health-risk information has no impact on behavior at all. See, e.g., Arlene Rubin Stiffman et al., Changes in Acquired Immunodeficiency Syndrome-Related Risk Behavior After Adolescence: Relationships to Knowledge and Experience Concerning Human Immunodefiency Virus Infection, 89 PEDIATRICS 950, 950, 954 (1992) (describing an empirical study conducted by the Harvard Medical School and the Washington School of Social Work with over six-hundred participants in which "[k]nowledge about AIDS or HIV infection and its prevention was not associated with any change in risk behavior," and noting that the findings of this study "reinforce the results of other studies that find no association between knowledge and risk behaviors"). These findings are not limited to the United States. See, e.g., Etsé Ditri Sallah et al., Comportements sexuels, connaissances et attitudes des étudiants de l'Université du Bénin (Togo) face au sida et aux maladies sexuellement transmissibles [The Sexual Behavior, Knowledge and Attitudes Towards AIDS and Sexually Transmitted Diseases of Students at the University of Benin (Togo)], 9 CAHIERS SANTÉ 101 (1999) (reporting that "students were aware of the way in which HIV is transmitted and of what construes risky behavior, but there was nonetheless a high frequency of high-risk behavior"), http://www.auf.org/ revues/sante/2.99/etu5su.htm; Jonathan E. Volke \& Cheryl Coopman, Factors Associated with Condom Use in Kenya: A Test of the Health Belief Model, available at http://ari.ucsf.edu/pdf/Posters/volk.pdf (last visited Apr. 25, 2003) ("Perceived benefits, susceptibility, and severity were not found to be significantly related to sexual risk behavior.").

${ }^{21}$ See, e.g., Ross Buck et al., Emotion and Reason in Persuasion: Applying the ARI Model and the CASC Scale, J. BUS. RES. (forthcoming) (manuscript at 8) (documenting "the 
sharing needles, ${ }^{23}$ the relationship between values and behavior postulated by the cultural theory of risk helps to explain behavior in ways that escape traditional rational- and irrational-weigher models. ${ }^{24}$

Indeed, the last twenty years of health-education research is in many ways a history of the failure of traditional health-information models and the search for better, more effective ways to influence risky behaviors. It is for precisely this reason that social-norms marketing-in which health educators first investigate and then seek to transform perceptions of the social meaning of a product or practice, like condoms and condom usage ${ }^{25}$-is now widely employed by the CDC, ${ }^{26}$ NIDA, ${ }^{27}$ and NIMH. ${ }^{28}$ Social-norms marketing is effective because in

very strong relationships between reported emotions, relations exclusivity and condom use/nonuse," which are "consistent with the notion that emotional variables exert important influences on the decision to use or not use condoms"), available at http://www.sciencedirect.com/science/journal/01482963.

${ }^{22}$ See, e.g., Helena Hansen et al., The Economy of Risk and Respect: Accounts by Puerto Rican Sex Workers of HIV Risk Taking, 39 J. SEx RES. 292, 292 (2002) (describing the importance of attending to cultural meaning "replete with competing risks and rewards on physical, economic, and moral planes").

${ }^{23}$ See, e.g., Philippe Bourgois, Theory, Method and Power in Drug and HIV-Prevention Research: A Participant-Observer's Critique, 34 SuBSTANCE USE \& Misuse 2155 (1999) (showing how health-educational approaches fail to change risky behavior among injection drug users where that behavior expresses important moral qualities).

${ }^{24}$ See Gilbert J. Botvin et al., The Effectiveness of Culturally Focused and Generic Skills Training Approaches to Alcohol and Drug Abuse Prevention Among Minority Adolescents: TwoYear Follow-Up Results, 9 PSYCHOL. ADDICTIVE BEHAVS. 183, 192 (1995) (finding that "a culturally focused intervention ... was more effective than a more generic approach"); Karol L. Kumpfer, Effectiveness of a Culturally Tailored, Family-Focused Substance Abuse Prevention Program: The Strengthening Families Program, in NATIONAL CONFERENCE ON DRUG Abuse Prevention Research 101 (Susan L. David ed., 1997) (reporting on the effectiveness of culturally sensitive family intervention programs in reducing substance abuse).

${ }^{25}$ See Susan E. Middlestadt et al., Beginning with Behavior: Research to Reduce Risk, in A WORld Against AIDS: COMMUNiCATION FOR BEHAVIOR CHANGE 37, 43 fig.2 (William A. Smith et al. eds., 1993) (showing that condom users and nonusers have similar levels of perceived risk but widely divergent perceptions of social norms); see also id. at 61-62 (" $[\mathrm{L}]$ evel of knowledge about transmission and prevention was rarely and only slightly related to the practice of safer behavior.").

${ }^{26}$ See AIDS Community Demonstration Projects: A Successful Community-Level Intervention to Reduce HIV Risk, Div. of HIV/AIDS Prevention, Ctr. for Disease Control \& Prevention, at http://www.cdc.gov/hiv/projects/acdp/ (last updated Apr. 5, 1999) (describing a campaign that successfully employed social-norms marketing techniques to increase condom usage); see also LyDia OGDEN ET AL., The PREvention Marketing INITIATIVE: APPLYING PREVENTION MARKETING (1996) (applying private-sector marketing techniques to public health initiatives to create a "social marketing-based program [that] 'sells' behaviors that benefit both the individual and society").

${ }^{27}$ Karol L. Kumpfer, Identification of Drug Abuse Prevention Programs: Literature Review, Nat'l Inst. on Drug Abuse, at http://www.drugabuse.gov/about/organization/ 
these areas (as in the gun debate) people follow the lead of others whom they perceive to be like them in relevant respects. ${ }^{29}$ If they think that those whom they respect or identify with are using condoms, they are far less likely to see condom usage as expressing something deviant or abnormal and, as a result, are far more likely to use condoms themselves. ${ }^{30}$

The lesson that our national health agencies have learned (at great expense in both human and material terms) is that health education campaigns are most effective when tailored to the specific cultural mores of at-risk groups. We are unsurprised that researchers have found that individuals often care more about what activities like smoking and condom use express about them than about what those activities do to them. That is precisely what the cultural theory of risk

hsr/da-pre/KumpferLitReview.html (last visited Apr. 7, 2003) (describing studies showing that "the most essential ingredient for success [in drug abuse prevention programs] appears to be changing social norms or peer norms"); Stewart I. Donaldson et al., Drug Abuse Prevention Programming: Do We Know What Content Works?, 39 AM. BEHAV. SCIENTIST 868, 878 (1996) (arguing that "studies do indicate that social-influencesbased drug abuse prevention programming in general, and changing social norms in school and community settings more specifically, can be highly effective").

28 See Research on Social Networks and HIV Risk Prevention, Nat'l Insts. of Health (Mar. 15, 2001), at http://grants.nih.gov/grants/guide/pa-files/PAS-01-068.html (describing a National Institute of Mental Health program devoting over a million dollars to social-norms marketing AIDS \& HIV prevention campaigns in 2001); NIMH Collaborative HIV/STD Prevention Trial, Nat'l Inst. of Mental Health (Apr. 15, 1999), at http://grants1.nih.gov/grants/guide/rfa-files/RFA-MH-99-011.html (describing similar programs in 1999); see also Prevention Project: Condom Social Marketing Intervention for African American Men, AIDScience Prevention \& Vaccine Research, at http://aidscience.org/Preventionproject.asp?ID=647 (last visited Mar. 26, 2003) (describing an NIMH-funded program to "[d] evelop a comprehensive condom social marketing intervention").

${ }^{29}$ See, e.g., Eleanor Matticka-Tyndale, Social Construction of HIV Transmission and Prevention Among Heterosexual Young Adults, 39 SOC. Probs. 238, 248 (1992) ("When condom use occurs in the context of a peer support system, condoms are acceptable. When peer norms reject condoms, condoms are not used."); see also Peer Volunteer Networks, Ctr. for Disease Control \& Prevention, Div. of HIV/AIDS Prevention, at http:// www.cdc.gov/hiv/projects/acdp/peer.htm (last updated Apr. 5, 1999) (describing the use of peer volunteers in marketing condom usage). The effectiveness of social-norms marketing extends to tobacco, alcohol, and substance abuse prevention as well. See, e.g., Michael P. Haines, A Social Norms Approach to Preventing Binge Drinking at Colleges and Universities, Higher Educ. Ctr. for Alcohol \& Other Drug Prevention (1996), at http://www.edc.org/hec/pubs/socnorms.html (describing a successful social norms campaign to reduce binge drinking sponsored by the U.S. Department of Education).

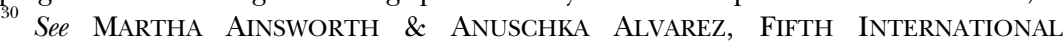
CONFERENCE ON AIDS IN ASIA AND THE PACIFIC 3 (1999) (describing condom usage as a result of "the success of Thailand's very strong preventive program in changing social norms"), available at http://www.worldbank.org/eapsocial/library/btoaids.pdf. 
predicts. What does surprise us is that Cook and Ludwig would imagine the gun debate to be any different.

\section{WHERE THERE'S A SMOKING GUN, THERE'S FIRE}

Focusing, predictably, on our regression analysis, our econometrician critics (both pro- and anticontrol) argue that we just haven't made the case that empirical information lacks the power to persuade on gun risks. Our regression model demonstrates that individuals' cultural orientations exert a significant influence on their gun control positions. But the model doesn't contain any direct measure of the impact of empirical information. So why infer that only culture, and not both culture and empirical data, matter?

This critique misconceives the nature of our proof and the contribution the GSS regression analysis makes to it. The cultural theory of risk perception comprises a collection of overlapping mechanisms that make empirical beliefs derivative, both morally and cognitively, of an individual's worldview. The distinctive signature of this mode of belief formation is a correlation between competing factual beliefs and individuals' cultural orientations. The existence of such a correlation thus furnishes not direct but rather compelling circumstantial proof of the inefficacy of empirical data. It's the smoke-or perhaps here, the smoking gun-that warrants one's confidence that empirical risk beliefs are being forged in a social-meaning fire.

The chain of reasoning here parallels the one we used to show how Cook and Ludwig's data substantiates the cultural basis of smoking- and unsafe-sex-risk perceptions. If individuals processed information on gun risks in the manner suggested by either the rationalweigher or irrational-weigher models, there would be no cultural bias in the distribution of views, for there is no reason to suppose that either information on gun risks or the capacity to understand and act on such information is distributed unevenly across individuals of divergent worldviews. Only the cultural-evaluator model predicts the clustering of gun-risk perceptions with cultural orientation. Accordingly, once such a clustering is observed, it's reasonable to infer that individuals conform their gun-risk perceptions to their cultural priors in much the same way that they do with their smoking- and unsafe-sexrisk perceptions.

Moreover, like Cook and Ludwig's (unwitting) proof of the cultural grounding of smoking- and unsafe-sex-risk perceptions, our proof of the cultural groundings of gun-risk perceptions is corroborated by additional evidence. As we pointed out in our main article, 
studies have consistently found that the sorts of experiences and beliefs that one would expect to be significant if individuals were motivated by instrumental or crime-control concerns turn out to have little or no impact on individuals' gun control positions, particularly once demographic characteristics are controlled for. ${ }^{31}$

All this said, we would happily agree that the impact of empirical evidence on gun control warrants continued investigation and study. ${ }^{32}$ But we would have thought that good empiricists such as Cook, Ludwig, Lott, Fremling, and Mustard would have agreed with us that a priori conjectures and personal anecdotes do not convincingly respond to the empirical evidence we've already compiled.

\section{III. $R^{2}$ ENVY}

The econometricians also taunt us for what they see as the limited power of our statistical analysis. Our regression model tests the significance of cultural orientation relative to other influences on individual positions on gun control. The total amount of the variance in individual positions explained by all of these influences considered in total-the " $R$ " value of our GSS regression-is .08. How can we draw strong conclusions from "measures [that] ... only explain $8 \%$ of the variation in people's attitudes toward gun control," Cook and Ludwig ask ? $^{33}$ Pointing out that the addition of cultural orientation variables increases the $R^{2}$ by only .016 , Lott and Fremling proclaim that our model should be viewed as demonstrating that "cultural worldviews' don't explain people's views on gun control" to any appreciable degree. $^{34}$

These are fairly technical criticisms. Is there a straightforward way to illustrate the practical importance of our model's $R^{2}$ value?

31 See Kahan \& Braman, supra note 1, at 1315 (arguing that "individuals' attitudes toward gun control are not based solely on their beliefs about the impact of gun control on public safety").

${ }^{32}$ As we stated in our main article, experimental evidence suggests that empirical evidence on the deterrent efficacy of the death penalty doesn't persuade. Individuals either conform their view of the persuasiveness of such evidence to their prior, noninstrumental beliefs about the appropriateness of the death penalty, or deem noninstrumental considerations sufficient to support their prior views no matter what the empirical evidence shows. Id. at $1316 \&$ n.77. We are currently engaged in research to adapt these experiments to gun control opinion.

${ }_{33}$ Cook \& Ludwig, supra note 2, at 1331.

${ }^{34}$ Gertrud M. Fremling \& John R. Lott, Jr., The Surprising Finding That "Cultural Worldviews" Don't Explain People's Views on Gun Control, 151 U. PA. L. REV. 1341, 1341 (emphasis added). 
Imagine that scientists conducted an experiment to test the effectiveness of a new drug on an often fatal disease. Suppose further that $64 \%$ of those who received the drug, but only $36 \%$ of those who didn't, survived. Receiving the drug would have increased the survival rate of treated patients by $78 \%$, an amount that any physician, not to mention any person with the disease, would consider tremendously important. Yet the $R^{2}$ for the experiment (here the amount of variance in the survival rates of those who received the new medication and those who did not) would have been only $.08^{35}$-precisely the $R^{2}$ value of our GSS regression analysis!

In the major leagues, career batting averages of .320 and .220 are worlds apart. They mark the difference between a premier performer who can expect a salary in the tens of millions and a hanger-on who is likely to be fighting to hold onto a backup role. But what is the $R^{2}$ of a model that uses batting average to explain the variation in the performance of these two skill levels in a particular at-bat? The answer is $.013,{ }^{36}$ a value smaller than the .016 variation in gun control attitudes across individuals explained by our cultural orientation scales. ${ }^{37}$

These examples teach a lesson that all social scientists know: to determine the importance of the percentage of variation explained, one "must be sensitive to the context of the data." Statistical concepts for characterizing degrees of correlation are abstractions; the consequences of particular correlations are not. If we have reason to believe that a small statistical effect will generate a large practical one, the idea that the former should be dismissed because it "accounts for

${ }^{35}$ Robert Rosenthal \& Donald B. Rubin, A Note on Percent Variance Explained as a Measure of the Importance of Effects, 9 J. APPLIED SOC. PSYCHOL. 395, 395 (1979).

${ }^{36}$ See Robert P. Abelson, A Variance Explanation Paradox: When a Little Is a Lot, 97 PSYCHOL. BULL. 129, 132 (1985) (exploring the statistical implications of batting averages).

${ }^{37}$ In any event, Lott and Fremling's mathematics misinterprets our model. They conclude that "culture" explains only 1.6 percentage points of the variance in attitudes toward gun control by subtracting the $R^{2}$ of a model that consists only of demographic variables from the $R^{2}$ of one that includes our cultural orientation variables as well. Fremling \& Lott, supra note 34 , at 1343 . But, in fact, demographics are proxies for culture in the gun control debate. Accordingly, what culture "explains" is not the difference between the two sets of variables but the sum of them as reflected in a unitary model.

${ }^{38}$ Rosenthal \& Rubin, supra note 35, at 395 (1979); see also Deborah A. Prentice \& Dale T. Miller, When Small Effects Are Impressive, 112 PsYCHOL. BuLL. 160 (1992) (arguing for the expansion of methods to measure statistical strength by testing them against unlikely circumstances). 
only [a small fraction] of the variance is simply wrong." ${ }^{39}$ It's not the size of your $R^{2}$ that matters; it's what you do with it!

There is plenty of reason to believe that the results of our GSS regression produce important real-world consequences. As we explained, the clustering of gun control positions with cultural orientations is the signature of a particular mechanism of risk perception. ${ }^{40}$ Where that mechanism is at work, simple appeals to empirical data won't change individuals' minds, or at least won't do so if presented in a way that is unconnected to the group allegiances and values that determine what evidence of risk individuals accept and what practical importance they attach to those risks. The supposedly low $R^{2}$ of our regression model doesn't detract from the significance of this finding.

One of the reasons that it's misleading to focus on the $R^{2}$ value in our model is that the practical importance of variance explained is "conditional on the degree to which the effects of the explanatory factor cumulate in practice." ${ }^{41}$ A model that uses batting skill to explain differences in performance across individual at-bats understates the difference a high batting average makes over the course of a season, in which a hitter comes to the plate hundreds of times and combines his efforts time and again with numerous other players (themselves varying in skill) to produce runs. Individual opinions likewise influence political outcomes through aggregation: it's the patterns that emerge as masses of individuals vote, express themselves, donate money to political causes, and the like that determine the profile and course of a public issue. Thus, even a modest amount of variation in opinion across individuals will profoundly influence collective deliberations.

In addition, we could have pumped up the $R^{2}$ for our model simply by incorporating additional independent variables. It is well known that adding variables drives up the percentage of variance explained, even when the inclusion of those variables doesn't genuinely increase a model's explanatory power. For example, whether one owns a gun and whether one's parents did are both extremely powerful predictors of one's attitude toward gun control. But these characteristics don't really "explain" variance in gun control attitudes; they just beg for an explanation of variance in gun ownership. Indeed, even variables that don't bear any statistically significant relationship

\footnotetext{
${ }^{39}$ Rosenthal \& Rubin, supra note 35, at 395.

${ }^{40}$ See supra Part II (defending a cultural-evaluator model for explaining perceptions of gun risk).

${ }^{41}$ Abelson, supra note 36, at 133.
} 
to the dependent variable will reduce the amount of unexplained variance in a regression. It is precisely because the $R^{2}$ value is sensitive to overspecification of this sort that social scientists don't, as a general matter, regard a high $R^{2}$ as tremendously informative.

Our econometrician critics have missed the mark. At every turn we have found the influence of culture to be far more powerful than other available and competing explanations of gun control attitudes. From previous statistical inquiries, to historical and ethnographic investigations, to our own data, we have discovered evidence that cultural orientations have a great deal more to do with how persuasive citizens find arguments about gun control to be than do other variables. Remarkably, in all these accounts and data, we have also found no evidence that statistics have any influence. ${ }^{42}$ Our factual fusileers can stick to their guns if they like. But to convince anyone who wants convincing of the power of statistics in the gun debate, they'll need better ammunition and aim.

\section{Culture Theory Heretics?}

Although agreeing with us that gun control is the sort of issue that the cultural theory of risk will best explain, Mary Douglas expresses some unease with our statistical proof. Our use of attitudinal measures, she worries, disregards the "specifiable institutional forms" associated with distinct ways of life. ${ }^{43}$ The measures we use to distinguish hierarchical from egalitarian ways of life, in particular, imply that the former consists of "bigotry, sexism, and racism." ${ }^{\text {"4 }}$ And because hierarchists favor governmental authority, she argues that individuals of a hierarchical orientation should "line up in favor of control," not against it as we hypothesized. ${ }^{45}$

Douglas is the high priestess of cultural theory. Her criticisms, however gently framed and constructively offered, raise for us the discomfiting specter of excommunication. We are thus eager to demonstrate the fit between our methodology and culture-theory orthodoxy-although we are also prepared to confess the sins of some of our ways in the hope that Douglas and other cultural theorists can

42 Again, discounting the personal anecdotes of the commentators.

${ }^{43}$ Mary Douglas, Being Fair to Hierarchists, 151 U. PA. L. REV. 1349, 1357 (2003).

${ }^{44} I d$. at 1362.

${ }^{45} \mathrm{Id}$. at 1361; see id. (proposing that the inclination to favor state authority would translate to support by hierarchists for state regulation of guns). 
help us to reform and improve as we continue to pursue this line of research. ${ }^{46}$

Start with a thumbnail sketch of the cultural theory of risk. According to Douglas's famous typology, cultures or "ways of life" can be characterized along two cross-cutting dimensions: "group," which represents the "extent to which "the individual's life is absorbed in and sustained by group membership,"”47 and "grid," which represents "the extent to which people's behavior is constrained by role differentiation." ${ }^{\prime 8}$ The location of a way of life within this framework is reflected in its "social relations"-how individuals interact with one another-and its "cultural bias"-its "shared values and beliefs" or "worldview." Through interrelated cognitive and social processes, ways of life generate competing schemes of risk perception: "Of all the things people can worry about, they will be inclined to select for particular attention those risks that help to reinforce" their way of life. $^{50}$

The method we employed in our regression model furnishes one sort of empirical test of this theory. We identified positions or attitudes that we thought were likely to divide individuals depending on whether they held worldviews that were more or less "group" and more or less "grid" within Douglas's framework. These were the basis of our individualist-solidarist and hierarchy-egalitarian scales. Consistent with the theory, we found that individuals' worldviews so measured did in fact significantly predict their gun control positions, which we took to be representative of their perceptions of competing types of "gun risks" (including accident and vulnerability to aggression). ${ }^{51}$

In answer to Douglas's concern, we would argue that this methodology should not be seen as ignoring the grounding of distinctive ways of life in particular institutional forms or social relations. Within

\footnotetext{
${ }^{46}$ With support from the National Science Foundation, we will conduct a national survey on guns and culture over the course of the next two years. We are currently developing more refined measures of cultural orientation for use in the survey.

47 Michael Thompson et al., Cultural Theory 5 (1990) (quoting Mary DOUGLAS, Cultural Bias, in In THE ACTIVE VOICE 183, 191 (1982)).

48 Jonathan L. Gross \& Steve Rayner, Measuring Culture: A Paradigm for THE ANALYSIS OF SOCIAL ORGANIZATION 6 (1985).

${ }^{49}$ See id. (using group-grid typology as a classification system for ways of life so defined).

${ }^{50}$ Steve Rayner, Cultural Theory and Risk Analysis, in SOCIAL THEORIES OF RISK 83, 91 (Sheldon Krimsky \& Dominic Golding eds., 1992).

${ }^{51}$ See Kahan \& Braman, supra note 1, at 1309 ("[D]ifferences in cultural orientations supply the most powerful explanation of why Americans disagree about whether and how to regulate guns.").
} 
cultural theory, social relations and worldviews "are reciprocal."52 That is, "[a]dherence to a certain pattern of social relationships generates a distinctive way of looking at the world; adherence to a certain worldview legitimizes a corresponding type of social relations. ${ }^{53}$ Thus, if the theory is correct, one should be able to predict an individual's risk perceptions equally well from either the social relations that characterize her life or her worldview. ${ }^{54}$ At least some cultural theorists have tried to identify observable behavioral measures of social relations. ${ }^{55}$ But we decided to treat worldview as our independent variable, in part because a greater number of past researchers have proceeded this way $^{56}$ and in part because we have better data from which to construct worldview measures.

We also think it would be a mistake to infer that we are equating any particular set of attitudes with a worldview. Obviously, an individual's worldview is not open to direct inspection. Thus, a researcher must identify some observable proxy or set of proxies for worldview if worldview is to be treated as an explanatory variable in a statistical model. The items that make up our individualist-solidarist and hierarchical-egalitarian scales are such proxies. The assumption is that there should be a strong correlation between scores on these scales and an individual's worldview, even though the individual items that make up the scales do not come close to capturing the richness and nuance of the fully specified worldviews that they represent.

${ }^{52}$ ThOMPSON ET AL., supra note 47 , at 1.

${ }^{53} \mathrm{Id}$.

${ }^{54}$ See, e.g., Mary Douglas, Introduction to GROSS \& RAYNER, supra note 48, at xvii, xxi ("Grid/group analysis is part of an approach whose data are either actions or statements in defense of actions.”).

${ }^{55}$ See GROSS \& RAYNER, supra note 48 (developing a fictitious case study to demonstrate that grid/group analysis could be used operationally to examine culture as a regulatory mechanism for behavior).

${ }_{56}$ See, e.g., Karl Dake, Orienting Dispositions in the Perception of Risk: An Analysis of Contemporary Worldviews and Cultural Biases, 22 J. Cross-Cultural PsyChOL. 61, 62 (1991) (arguing that "mental modes of risk ... correspond to worldviews" in support of measuring such views to predict public perceptions of risk); Hank C. Jenkins-Smith \& Walter K. Smith, Ideology, Culture, and Risk Perception, in POLITICS, POLICY, AND Culture 17 (Dennis J. Coyle \& Richard J. Ellis eds., 1994) (analyzing the relationship among an array of factors including cultural bias to show the foundations of judgments about risk); Jenkins-Smith, supra note 10, at 111-13 (incorporating "items measuring aspects of cultural bias" in a study on the stigmatizing effects of nuclear images in Nevada); Ellen Peters \& Paul Slovic, The Role of Affect and Worldviews as Orienting Dispositions in the Perception and Acceptance of Nuclear Power, 26 J. APPLIED SOC. PSYCHOL. 1427, 1431 (1996) ("Worldviews then may be one system for assessing value."). 
It should not be inferred that we think that ours is the only method for testing cultural theory or even necessarily the best one. Ethnographic and historical case studies furnish another approach. ${ }^{57}$ These methods generate a much richer apprehension of cultural ways of life than do survey instruments based on either social relations or worldviews. But they do so at the expense of the rigor, precision, and relative objectivity afforded by survey methodology. In short, every method has both advantages and disadvantages. The ideal way to test cultural theory, then, isn't to rely on any single empirical method but to rely on as many as possible to see if they generate consistent and mutually supportive insights.

Having defended our method, however, we also want to acknowledge the merit of Douglas's concerns with our attitudinal measures of hierarchy. Hierarchical or "high grid" ways of life are ones in which fixed forms of social differentiation-ones not open to individual negotiation-loom large in the distribution of resources, opportunities, respect, and the like. ${ }^{58}$ Because gender and race are salient forms of social differentiation, it stands to reason, we think, that attitudes that denote resistance to racial and gender discrimination (including discrimination based on sexual orientation) are less likely to be held by those of a hierarchical than those of an egalitarian worldview. ${ }^{59}$ But it

\footnotetext{
${ }^{57}$ See, e.g., Steven M. Teles, Whose Welfare? AFDC And Elite Politics (1998) (using a historical-interpretive method to explain political disputes over welfare policy in the United States).

${ }^{58}$ See, e.g., Rayner, supra note 50, at 87 ("Grid is defined as a measure of the constraining classifications that bear upon members of any social grouping. Such classifications may be functions of hierarchy, kinship, race, gender, age, and so forth." (emphasis omitted)).

${ }^{59}$ Cf. AARON Wildavisky, THE Rise OF RAdicAl EgAlitarianism 22 (1991) (suggesting that egalitarians and hierarchists will divide over the importance of "diminishing distinctions among people such as wealth, race, gender, authority and so forth"). Wildavsky saw the status of gays as another issue likely to divide hierarchists and egalitarians. Indeed, he suggested that these orientations would, correspondingly, influence how individuals viewed the risk of the transmission of HIV through casual contact:

The more hierarchical the group, I hypothesize, following cultural theory, the more it minimizes technological danger as the price of progress while maximizing fear of casual contact with people who have AIDS. For, in its view, when people violate divine commandments, the Lord brings plague. Conversely, egalitarians tend to grossly overestimate the dangers from technology (on grounds that the social and economic relations they dislike are bad for your health) while minimizing the dangers from casual contact with carriers of AIDS. Gays are good in the egalitarian view because they are antiestablishment and because they reduce differences among people. Only cultural theory explains why, when we know a group's ideology, we can tell how much danger they will impute to technology versus AIDS.
} 
would clearly be a mistake to reduce hierarchy to sexism and racism; the hierarchical worldview is obviously richer and more subtle than that. Moreover, the conspicuous moral disapprobation that racist and sexist attitudes provoke makes using them even as proxies for hierarchy extremely problematic. The inclusion of such items not only conveys (tendentiously) that " $[\mathrm{s}]$ omebody here doesn't like hierarchists" ${ }^{60}$ it also inevitably understates the representation of hierarchists in the subject pool: even racists and sexists, not to mention hierarchically inclined individuals who are neither, can be expected to deny that they hold discriminatory attitudes when responding to survey questions. ${ }^{61}$

Aaron Wildavsky wrote that of all the cultural types, "[h]ierarchists are least likely to admit to their cultural leanings, for they know these are reviled" by many in American society. ${ }^{62}$ Surveyors who want to study culturally grounded political conflict-not to mention contribute to the civilized resolution of it-need to develop survey measures benign enough to draw the hierarchists out of the closet. We're grateful to Douglas for focusing our attention on the problem. We'd be even more grateful were she and other cultural theorists to help us to figure out a way to solve it.

We don't, however, plan to back off our hypothesis that hierarchists, in the United States, should oppose gun control. Douglas's counter-hypothesis-that hierarchists should be procontrol because they are proauthority-understates the adaptability of the cultural theory of risk to local and historical circumstance. Wildavsky, for example, argues that the attitudes of hierarchists, egalitarians, and individualists toward a strong national government have shifted over the course of American history in response to the efforts of each to use government to advance its respective way of life and suppress those of its cultural adversaries. ${ }^{63}$ Indeed, Culture and Risk itself rejects any simple identification of hierarchy with support for governmental authority: it was the hierarchists in Douglas and Wildvasky's view who opposed comprehensive government regulation of environmental and technological

\footnotetext{
Aaron Wildavsky, Choosing Preferences by Constructing Institutions: A Cultural Theory of Preference Formation, 81 AM. POL. SCI. REV. 3 , 15 (1987).

${ }^{60}$ Douglas, supra note 43, at 1362.

${ }^{61}$ See Paul M. Sniderman et al., The New Racism, 35 Am. J. PoL. SCI. 423, 423 (1991) (noting that while "[b]latant racism ... is on the wane," discriminatory attitudes still exist and are experimentally verifiable).

${ }^{62}$ WILDAVSKY, supra note 59, at xxix.

${ }^{63} I d$. at $32-45$.
} 
risk because of the challenge to the competence and authority of traditional elites that environmentalism symbolized. ${ }^{64}$

Cultural theory, in our view, implies that competing worldviews will generate competing perceptions of risk (and competing political positions generally) but leaves it to history, which imbues risks with social meanings, to determine exactly what those differences will be about. Over the course of American history, guns — and in particular, the normality of owning one-have become woven into the texture of a hierarchical way of life. They are part of the symbolic equipment (particularly in the South) that enables men to occupy distinctively male roles (father, hunter, protector) and exhibit distinctively male virtues (courage, honor, responsibility, martial prowess). ${ }^{65}$ They are the badges of institutions (the military, the police) that are themselves hierarchic and that are seen as aligned with traditional elites. ${ }^{66}$ It is precisely these social meanings that make individuals of an egalitarian orientation wary of guns and attentive to their risks. And it is precisely the conspicuous egalitarian resonances of gun control that make hierarchists discount such risks and instead fret about the dangers that disarming the upright and the virtuous can pose to social order.

\section{Closet Liberals?}

Sandy Levinson is aggrieved by our attack on liberalism. He thinks that we not only unfairly caricature liberalism but falsely disclaim the liberal nature of our own position. "[L]iberalism," he tells us, is about describing "how legitimate public decisions can be made

${ }^{64}$ DOUGLAS \& WILDAVSKY, supra note 6. As Wildavsky summarized the argument, "the debate over risk stemming from technology is a referendum on the acceptability of American institutions," one in which hierarchists, as defenders of traditional authority, are naturally disposed to oppose regulation. Wildavsky, supra note 59, at 14 .

${ }^{65}$ See generally William R. TONSO, Guns AND SOCIETY: THE SOCIAL AND EXISTENTIAL RoOTS OF THE AMERICAN ATTACHMENT TO FireARMS 34-38 (1982) (discussing the masculine symbolism of guns); Claire A. Cooke \& John E. Puddifoot, Gun Culture and Symbolism Among U.K. and U.S. Women, 140 J. SOC. PSYCHOL. 423, 424 (2000) ("The view of an essentially masculine 'gun culture' is supported by readily perceived regional differences in gun ownership, even within the boundaries of one nation.”); H. Taylor Buckner, Sex and Guns: Is Gun Control Male Control? (Aug. 5, 1994) (unpublished manuscript) (presenting evidence that gun use and ownership is male dominated), available at http://www.tbuckner.com/SEXGUN.HTM.

${ }^{66}$ Cf. Julian V. Roberts \& Loretta J. Stalans, Public Opinion, Crime, and CRIMINAL JUSTICE 287 (1997) (citing a study that indicates that confidence in police negatively correlates with support for gun control); JAMES D. WRIGHT ET AL., UNDER THE Gun: WEAPONS, CRIME, AND VIOLENCE IN AMERICA 118 (1983) (discussing the finding that veterans of the military are more likely to own a gun than nonveterans). 
in spite of the significant sociocultural fragmentation."67 "But," he continues, "this . . s seems to be Kahan and Braman's own project." 68

What we have in mind when we criticize "liberalism" is a set of discourse norms that counsel individuals to avoid appeals to contested cultural values when they engage in deliberation. ${ }^{69}$ Levinson doesn't deny that such norms exist and are influential. He need only look to how politicians, political scientists, and economists engage one another in the gun debate to see that. Instead, he seems to be arguing that, by default, because our goals are not those of cultural imperialism, we $m u s t$ be liberals. ${ }^{70}$ But are liberalism and cultural imperialism the only available alternatives?

Whatever Levinson thinks it should be called, we are advocating an alternative to the conventional "don't ask, don't tell" strategy of dealing with cultural conflict in law. We believe that culturally informed political conflicts are most likely to be resolved not when the law tries to be silent about disputed social meanings, but rather when it says so much about them that all sides are able to find support for their worldviews within it. Instead of trying to drain law of divergent meanings, we favor the creation of laws rich enough in meaning that they allow citizens of diverse orientations to find affirmation in those laws simultaneously. Where liberalism (or at least one conspicuous form of it) advocates an expressively inert idiom designed to generate overlapping consensus, ${ }^{71}$ we advocate an expressive pluralism that enables overlapping dissensus.

The difference between our goal and that of liberalism also means that we are interested in different methods. If, as we argue, the debate over gun control is to be solved by attending to the divergent social meanings that citizens attach to gun control, the way to work toward compromise is not by focusing on a narrow subset of shared

\footnotetext{
${ }^{67}$ Sanford Levinson, What Follows Putting Reason in Its Place? "Now Vee May Perhaps to Begin. Yes?," 151 U. PA. L. REv. 1371, 1381 (2003).

${ }^{68} \mathrm{Id}$.

${ }^{69}$ Indeed, the constraint on what counts as acceptable discourse is one of liberalism's central tenets and, arguably, greatest strengths. See, e.g., JOHN RAWLS, PoliticaL LIBERALISM 66-67 (1993) (describing the relevance of scientific thought to an "effective public conception of justice"); see also id. at 139 (arguing that "agreement on a political conception of justice is to no effect without a companion agreement on guidelines of public inquiry and rules for assessing evidence").

70 See Levinson, supra note 67, at 1381 ("On the basis of the content, if not the rhetoric, of their article, one could easily describe them as quintessentially 'liberal' in their call for deliberation based on the mutual respect of quite different worldviews.").

${ }^{71}$ See RAWLS, supra note 69, at 133-72 (describing the importance and mechanisms of "overlapping consensus" to liberal political theory).
} 
concerns. Instead, we anticipate that progress on the gun debate will be made only when citizens express the specific and divergent meanings that obtain for them in the gun debate. Working these divergent meanings into law and policy, we think, is the key to progress and, ultimately, legitimate decision making. This difference in approach also highlights why we are so concerned about attempts to reduce those divergent meanings to a single metric.

Levinson's second set of complaints has to do with what he takes to be our simultaneous use and dismissal of empirical evidence. ${ }^{72}$ This is easy to answer: We don't wish to dismiss the usefulness of empirical evidence, but rather to describe when it is useful and when it is counterproductive. In fact, one way to address Levinson's concern is to consider, in the language of economics, the potential benefits of attending to cultural concerns. Assume, as Cook and Ludwig do, that there is the potential for a reduction in social costs of up to one hundred billion dollars each year by implementing various regulatory reforms. $^{73}$ Now imagine one scenario in which citizens perceive their worldview to be more threatened by the policy implications of the statistical battle and another in which they feel less so. The lesson of cultural theory (and the public health literature) is that, in the former case, citizens are less likely to evaluate the statistical studies with any care and more likely to dismiss them when considering how to behave. $^{74}$ As a result, they are far less likely to adopt sensible harmreduction measures, whether through increased or decreased regulation of gun ownership. This, in turn, diminishes the overall impact of the "good ideas" that researchers identify. In fact, the information we do have about risk perception and political debates suggests that value conflicts and pervasive distrust in risk management cannot easily be reduced by technical analysis. ${ }^{75}$ Moreover, "[t]rying to address risk controversies primarily with more science is, in fact, likely to exacer-

${ }^{72}$ See Levinson, supra note 67, at 1382 (pointing out the self-contradiction of attacking empirical argumentation through statistics).

${ }^{73}$ See Cook \& Ludwig, supra note 2, at 1337-38 (estimating the cost of gun violence in the United States).

${ }^{74}$ For the illustration of this in public health literature, see supra notes $18-30$ and accompanying text. Other examples include public reactions to nuclear power and toxic waste. See, e.g., Peters \& Slovic, supra note 56, at 1448-51 (finding that attitudes toward nuclear power were "systematically related to a person's worldviews" and not merely an extension of exposure to specific information).

${ }^{75}$ SLOVIC, supra note 7 , at 411. 
bate conflict." ${ }^{76}$ The more we assume that empirical researchers get things right, the more paying attention to culture matters. ${ }^{77}$

Levinson's third set of complaints concerns the scope of our project: if we think that there is any chance of resolving the gun debate, why don't we simply tell the reader how we imagine that happening? ? $^{78}$ Our reason is essentially procedural. Our goal in the first step is not simply to show that culture matters, but to understand how it does and why. Getting this right is no small matter, and the subsequent process of constructing a richer vocabulary for public deliberation is predicated on its success. Had we gotten it wrong, there would be little point in proceeding to the second, deliberative step we envision. We are gratified that Levinson, someone who has thought longer and harder about gun control than most, thinks we got it right. ${ }^{79}$

\section{Conclusion: Even More Statistics, Even Less Persuasion}

Our commentators have thoughtfully prodded us into thinking about how our analyses might be improved, extended, and made use of. For this, we are grateful. But we were also, at least initially, perplexed about the strange pattern of opinions that emerged on the relative importance of culture and data in the gun debate. What, we wondered, could explain the strange congruence of opinion among staunch procontrollers like Cook and Ludwig and anticontrollers like Mustard, Lott, and Fremling - all of whom concluded that data matter most? What commonality could explain the agreement of a Texas law professor and a British social anthropologist that culture is in fact more important?

76 Id.

${ }^{77}$ There are, of course, other ways of responding to values-driven public deliberation. One suggested by commentators like Stephen Breyer and Howard Margolis is to privilege the views of experts over those of ordinary citizens, endowing them greater political authority. E.g., STEPHEN BREYER, BREAKING THE VICIOUS CIRCLE: TOWARD EFFEctive Risk REgulation (1993); HowARd MARgolis, DEALing With RisK: WHY THE Public AND The ExPERTS Disagree on ENVIRONMENTAL REgulation (1996). It has been further argued that the problem of public distrust, where not settled by the public's ignorance of potentially controversial policies, should be effected by manipulation of public opinion through known psychological mechanisms. See Sunstein, supra note 7, at 1168 ("If government cannot dissipate fear through information, it might be well advised to regulate, at least if regulation will eliminate fear in a relatively inexpensive manner.").

78 See Levinson, supra note 67, at 1378-79 (expressing disappointment that we do not provide an "actual structure" for an alternative to the current debate).

${ }^{79}$ See id. at 1376 ("[T] heir basic arguments feel right to me ...."). 
Committed as we are to furnishing empirical proof of the powerlessness of empirical proofs, we constructed a regression analysis to answer these questions. The results are provided below in Table 1. This final study-whether one accepts the results of it or not-conclusively proves our point that statistics are incapable of persuading anyone to accept anything they don't already believe.

Table 1: Demographics and Faith in Statistics ${ }^{80}$

\begin{tabular}{|c|c|c|}
\hline & Which Predominates & Culture or Statistics? \\
\hline & Model 1 & Model 2 \\
\hline Sex & $\begin{array}{l}0.03 \\
\quad(0.58)\end{array}$ & $\begin{array}{l}0.00 \\
\quad(0.00)\end{array}$ \\
\hline Age $^{\#}$ & $\begin{array}{l}-0.12 \\
\quad(0.02)\end{array}$ & $\begin{array}{l}0.00 \\
\quad(0.00)\end{array}$ \\
\hline Income $^{\#}$ & $\begin{array}{l}0.00 \\
\quad(1.15)\end{array}$ & $\begin{array}{l}0.00 \\
\quad(0.00)\end{array}$ \\
\hline Nationality & $\begin{array}{l}0.36 \\
\quad(0.43)\end{array}$ & $\begin{array}{l}0.00 \\
\quad(0.00)\end{array}$ \\
\hline Party $^{\#}$ & $\begin{array}{l}0.12 \\
\quad(0.43)\end{array}$ & $\begin{array}{l}0.00 \\
\quad(0.00)\end{array}$ \\
\hline Liberal/Conservative ${ }^{\#}$ & $\begin{array}{l}0.13 \\
\quad(0.43)\end{array}$ & $\begin{array}{l}0.00 \\
\quad(0.00)\end{array}$ \\
\hline Economist & & $\begin{array}{r}1.00 * * * \\
(0.00)\end{array}$ \\
\hline$R^{2}$ & 0.27 & 1.00 \\
\hline Observations & 7 & 7 \\
\hline
\end{tabular}

${ }^{*}$ Estimated. $\mathrm{R}^{2}$ represents Cox and Snell psuedo $\mathrm{R}^{2}$. Numbers in parentheses represent standard errors. * indicates p-value $<0.05$; ** indicates p-value $<0.01$; *** indicates p-value $<0.001$.

${ }^{80}$ The first column provides various demographic variables that other researchers have found to influence a wide range of attitudes. To these we have added a further demographic variable, "economist," a binary measure indicating whether or not a commentator regularly uses econometric methods to produce cost-benefit analyses. The second column provides the standardized betas of the variables in the model that includes the traditional demographic variables. The third column shows standardized betas for the more fully specified model in which our measure for "economist" is included. 